\title{
Numerical Investigation of Air-Side Heat Transfer and Fluid Flow in a Microchannel Heat Exchanger
}

\author{
Ubade Kemerli, Kamil Kahveci \\ Trakya University, Faculty of Engineering \\ Ahmet Karadeniz Campus, Edirne, Turkey \\ ubadekemerli@trakya.edu.tr; kamilk@trakya.edu.tr
}

\begin{abstract}
In this paper, air-side heat transfer and fluid flow in a compact microchannel was investigated numerically by a commercially available modelling and simulation software. The translational periodic boundary condition was used to reduce the computational cost. The results were obtained for four different fin pitch lengths and four different inlet velocities. The results were given by the heat transfer coefficient, the average Nusselt number, j-factor, pressure drop and contours of velocity and temperature. The results show that the heat transfer coefficient gets its highest value for the pitch length of $1 \mathrm{~mm}$. The decrease in the heat transfer coefficient gets lower values with the increase in the pitch length. It is observed that the average Nusselt number shows a considerable increase with an increase in the Reynolds number. The results also show that the j-factor shows an exponential decrease with an increase in the Reynolds number. Finally, the results show that the pressure drop shows a considerable decrease with an increase in the pitch length.
\end{abstract}

Keywords: Microchannel, heat exchanger, Nusselt number, pressure drop, $\mathrm{j}$ factor.

\section{Introduction}

Growing energy demand and growing competition in the engineering market together with developing technology, eliminates the heavy and inefficient products from the market and replaces more compact, recyclable and efficient products which give better performance. This development is clearly observed in heat exchanger technologies, which are the key element for the most of the engineering applications concerned with energy management. The desired qualifications for a heat exchanger are the performance, corrosion resistance, reduced pressure drop, reduced weight and price. Aluminium microchannel compact heat exchangers meet many of these qualifications, still with the need of further improvement of these qualifications.

There are a number of studies on the performance of microchannel heat exchangers in the literature. In one of these studies, Dasgupta et al. [1] made an experimental investigation on the air-side performance of a microchannel. They concluded that air-side Reynolds number plays a major role in heat transfer. They also proposed correlations for air-side average Nusselt number and friction factor. Siddiqui et al. [2] investigated the air-side heat transfer and fluid flow performances of a microchannel heat exchanger. Their results show different frontal air velocities altered in nine steps between $3 \mathrm{~m} / \mathrm{s}$ and $11 \mathrm{~m} / \mathrm{s}$. They also proposed correlations between Re-Nu and Re-f. Dehghandokht et al. [3] studied the effect of serpentine in a multi-port microchannel heat exchanger on heat transfer numerically. They validated their results with the experimental data. They concluded that the presence of an adiabatic serpentine bend causes $20 \%$ increase in heat transfer rate due to existence of a new entrance region. Oliet et al. [4] conducted a parametric study on automotive radiators. Harris et al. [5] designed a cross flow micro heat exchanger. They proposed three different heat exchangers: plastic, ceramic and aluminium. For the aluminium exchanger, they obtained a heat transfer rate of $59.4 \mathrm{~W} / \mathrm{cm}^{3}$. Khan and Fartaj [6] published a review study on microchannel heat exchangers. They emphasized that the studies on air-to-liquid microchannel heat exchangers are limited. They also made a survey on experimental infrastructures. Different fin geometries for air-side of microchannel heat exchangers can be found in the review study of Sheik Ismail et al. [7] Also a useful broad review about compact heat exchangers can be found in the study of Li et al. [8].

The aim of this study is to investigate air-side heat transfer and fluid flow in a compact microchannel for various values of inlet velocity and pitch value. 


\section{Method}

A microchannel heat exchanger is consisted of fins and multiport slabs. This construction periodically repeats itself inside the heat exchanger. Hence, the solution of single periodic element can be generalized to the whole system approximately. In this study, the heat exchanger examined was partitioned to translational periodic elements and the solution was obtained for one of these periodic elements.

As mentioned before, the subject of this study is to examine the air-side heat transfer and fluid flow characteristics of a microchannel heat exchanger. The temperature of the liquid in microports was assumed constant at $50^{\circ} \mathrm{C}$. This is the case when the condensation process occurs in the liquid side.

Fig. 1 shows the schematic view of the microchannel heat exchanger considered in this study. Fig. 2 shows one the translational periodic element of the heat exchanger. The heat exchanger was assumed to be $50 \mathrm{~mm}$ depth. Fin height is taken as $15 \mathrm{~mm}$. The microport slab of the exchanger has $2 \mathrm{~mm}$ height. Microports were assumed to have $1 \mathrm{~mm}$ diameter. The microports were modelled as a single elliptic tube as the heat transfer between tubes is negligibly small. The schematic view of the element considered is seen in Fig. 2.

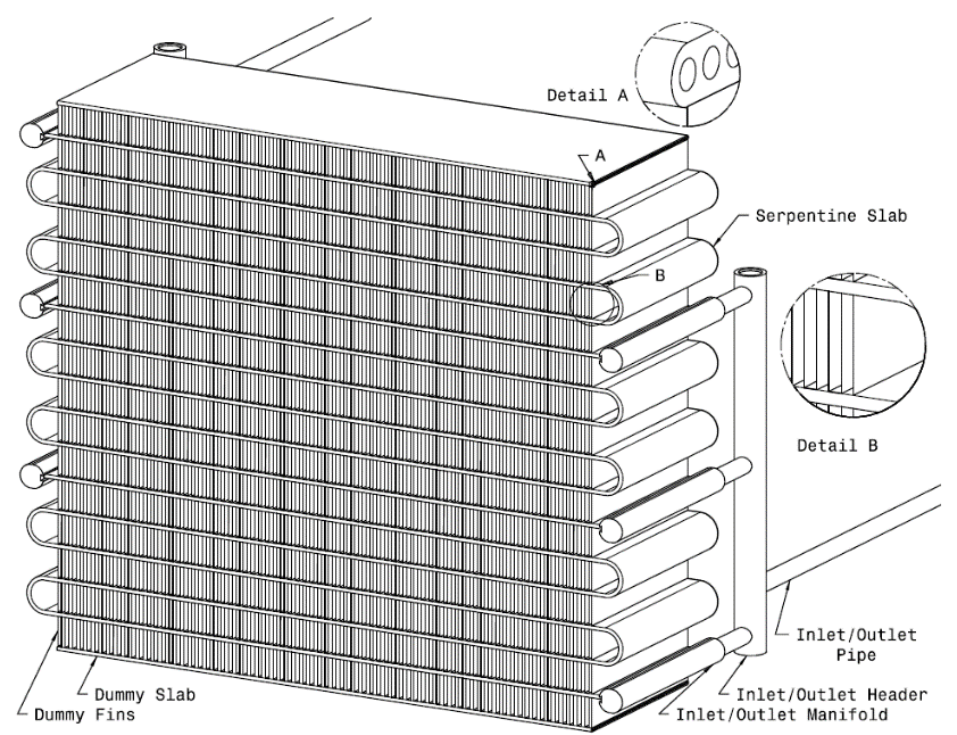

Fig. 1: Schematic view of the microchannel heat exchanger [9].

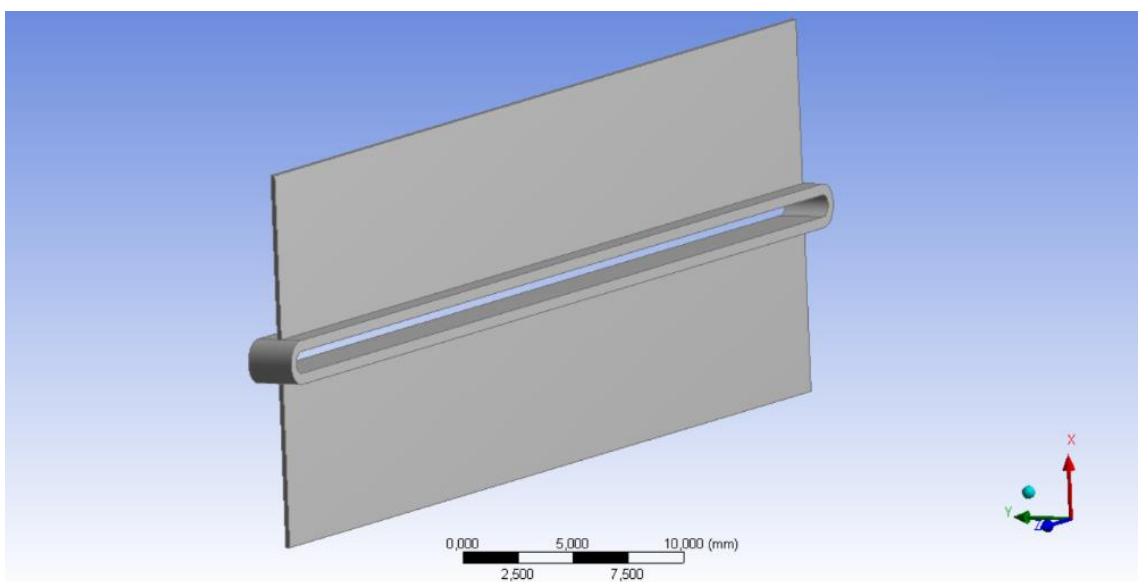

Fig. 2: Translational fin model.

The inlet velocity was taken as 2, 4, 6 and $8 \mathrm{~m} / \mathrm{s}$. Four different fin pitch values were considered: 1, 2, 3 and $4 \mathrm{~mm}$. The temperatures of the inlet air and the fin base were assumed as $25^{\circ} \mathrm{C}$ and $50^{\circ} \mathrm{C}$, respectively.

The heat transfer rate for the heat exchanger can be obtained by the following equation: 


$$
\dot{Q}=\mathrm{UAF} \Delta \mathrm{T}_{l m}
$$

where $\mathrm{F}$ is the correction factor, $\mathrm{U}$ is the overall heat transfer coefficient and $\mathrm{A}$ is the contact area between the air and the solid. As the constant temperature was assumed for the liquid side, the correction factor can be assumed as unity. The logarithmic temperature difference $\Delta \mathrm{T}_{l m}$ is defined as:

$$
\Delta \mathrm{T}_{l m}=\frac{\left(T_{m p}-T_{\text {in }}\right)-\left(T_{m p}-T_{\text {out }}\right)}{\ln \left(T_{m p}-T_{\text {in }}\right)-\ln \left(T_{m p}-T_{\text {out }}\right)}
$$

where $T_{m p}$ is the condensation temperature, which was taken as $50^{\circ} \mathrm{C}$ and $T_{\text {in }}$ is the inlet temperature of air, which was taken as $25^{\circ} \mathrm{C}$ in this study. $T_{\text {out }}$ is the average temperature of air at the outlet. As the resistance of aluminum and fluid side is negligible, total resistance can be expressed approximately as following:

$$
R_{a}=\frac{1}{U A}=\frac{\Delta \mathrm{T}_{l m}}{\dot{Q}}
$$

where $\dot{Q}$ is the total heat transfer on the contact region between the solid and the air.

The Reynolds number is defined as:

$$
\operatorname{Re}=\frac{\rho V D_{h}}{\mu}
$$

where $V$ is the inlet velocity of the air, $\rho$ and $\mu$ are the density and viscosity of the air respectively. $D_{\mathrm{h}}$ is the hydraulic diameter defined as:

$$
D_{h}=\frac{4 A_{c}}{p}
$$

where $A_{c}$ is the cross-section of flow between fins and $p$ is the wetted perimeter for mentioned cross-section. The thermal resistance of air is defined as:

$$
R_{a}=\frac{1}{\left(\eta_{a} h_{a} A_{a}\right)}
$$

where $\eta_{a}$ is the air-side surface efficiency, $A_{a}$ is the surface area and $h_{a}$ is the heat transfer coefficient for air. The air-side surface efficiency can be defined as following:

$$
\eta_{a}=1-\frac{A_{f}}{A_{a}}\left(1-\eta_{f}\right)
$$

As the plain rectangular fins are used, fin efficiency can be expressed by following equation [10]:

$$
\eta_{f}=\frac{\tanh (m L)}{m L}
$$

where $\mathrm{L}$ is the characteristic length and the fin parameter $\mathrm{m}$ is defined as following; 


$$
m=\sqrt{\frac{2 h_{a}}{k t}}
$$

where $\mathrm{k}$ is the thermal conductivity of the fluid and $\mathrm{t}$ is the thickness of the fin. The characteristic length can be defined as:

$$
L=\frac{H_{\text {fin }}}{2}-t_{\text {fin }}
$$

The $h_{a}$ was obtained iteratively by Eqs. (6)-(10) and Eq. (1). Then the average Nusselt number can be defined as:

$$
\mathrm{Nu}=\frac{h_{a} D_{h}}{k}
$$

\section{Results and Discussion}

The air-side heat transfer and fluid flow characteristics in a heat exchanger were investigated in this study for different fin pitch lengths and inlet velocities. The ANSYS Fluent modelling and simulation software was used to obtain computational results. The flow between the fins is laminar for the values of parameters considered in this study. On the other hand, the flow regime in the inlet and outlet zones is turbulent. Therefore, these domains were modelled by the kepsilon turbulence model.

The variation of the average heat transfer coefficient with the inlet velocity is seen in Fig. 3 for various values of the pitch length. The heat transfer coefficient gets its highest value for the pitch length of $1 \mathrm{~mm}$. A considerable decrease is seen in the heat transfer coefficient when the pitch length is increased from $1 \mathrm{~mm}$ to $2 \mathrm{~mm}$. This can be attributed to the decrease in velocity when the pitch length is increased. The heat transfer coefficient shows lower decreases with the further increase in the pitch length. Increasing the pitch length from $1 \mathrm{~mm}$ to $4 \mathrm{~mm}$ results in a decrease in the heat transfer coefficient between 44-60\% depending on the value of the Reynolds number. As it can also be seen in Fig. 3 that the heat transfer coefficient shows a considerable increase with an increase in the inlet velocity as the convection gets stronger.

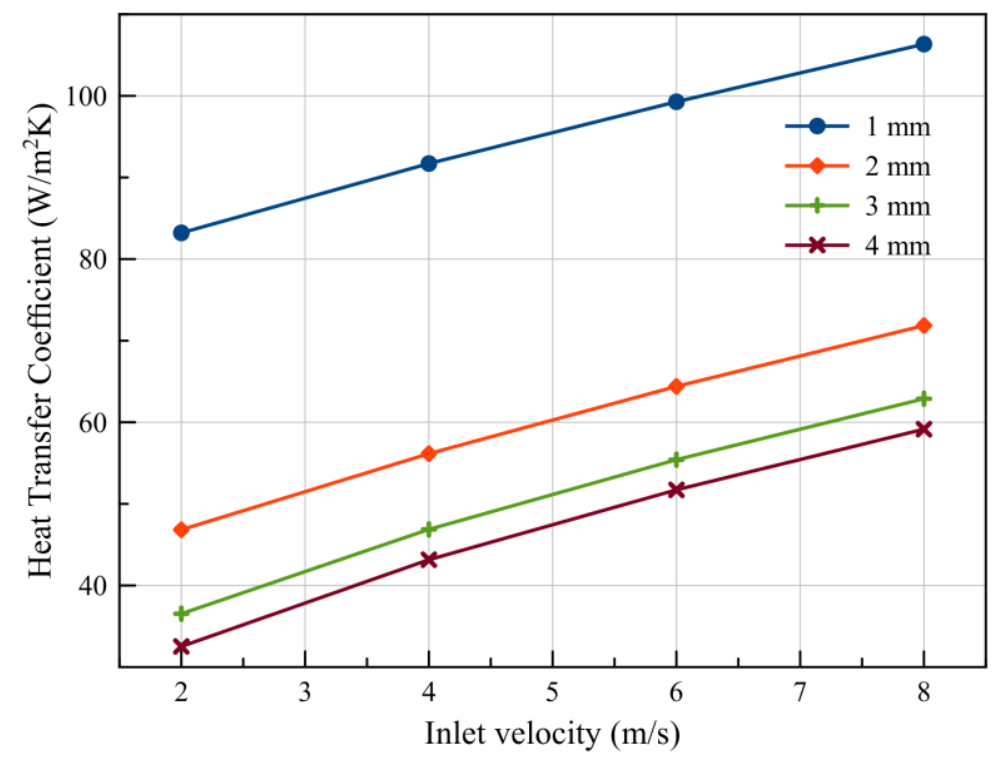

Fig. 3: Variation of heat transfer coefficient with inlet velocity. 
The variation of the average Nusselt number with the Reynolds number is seen in Fig. 4 for various values of the pitch length. As it can be seen from Fig. 4, that the average Nusselt number shows a considerable increase with the Reynolds number, as expected. The average Nusselt number is a non-dimensional form of the average heat transfer coefficient. However, as opposed to the heat transfer coefficient, the average Nusselt number shows an increase with an increase in the pitch length. This is because of the fact that the pitch length is used in the non-dimensionalization of the heat transfer coefficient and an increase in the pitch length causes an increase in the average Nusselt number.

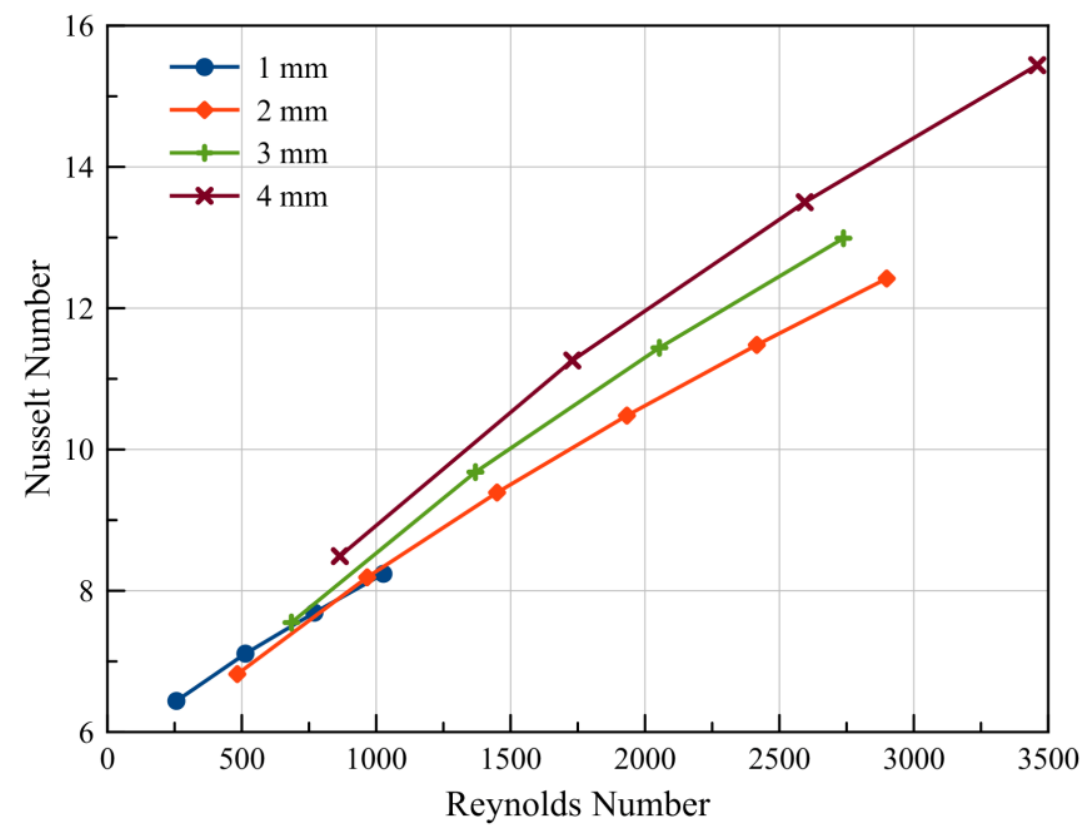

Fig. 4: Variation of Nu number with Re number.

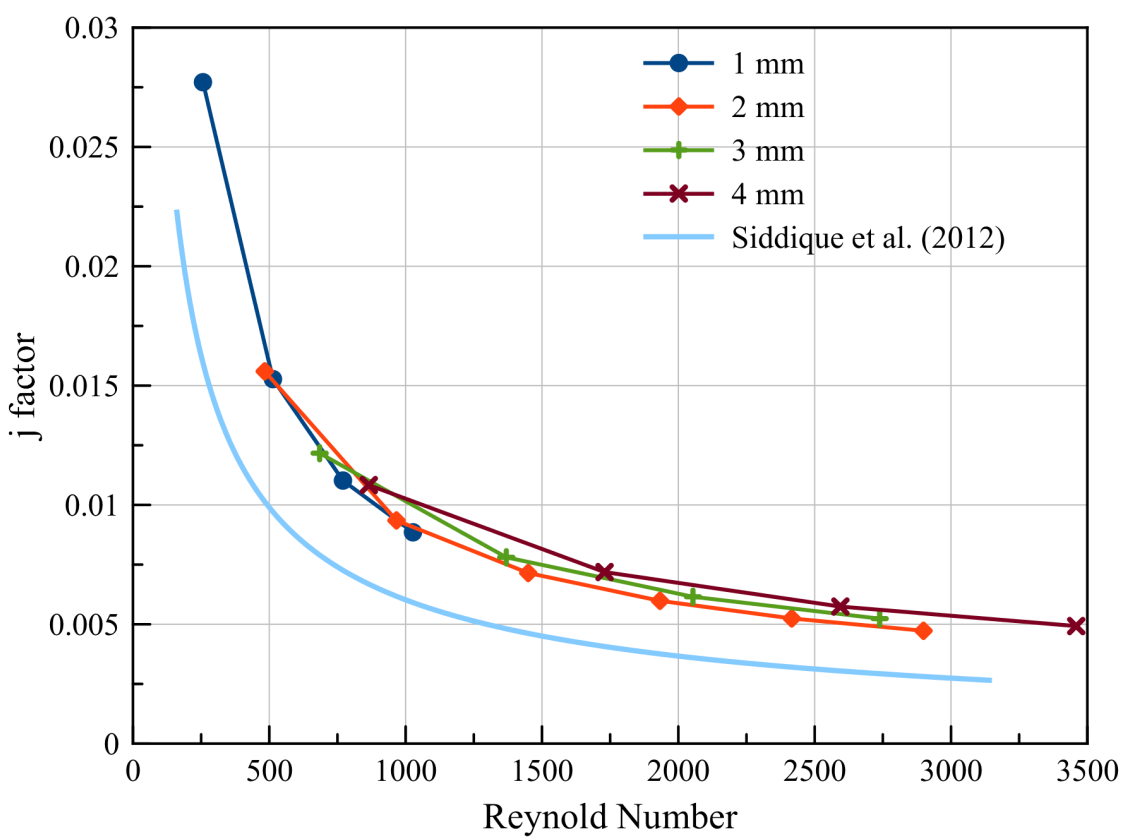

Fig. 5: Variation of $\mathrm{j}$ factor with Re number. 
The average Nusselt number does not give any information on the heat transfer per thermal capacity of the fluid. Therefore, the $\mathrm{j}$-factor found a widespread use in many heat transfer analyses to characterize heat transfer. Fig 5 . shows the variation of $j$ with the Re number for various values of pitch length. As it can be seen from Fig. 5, that the $j$-factor shows an exponential decrease with an increase in the Reynolds number and approaches zero asymptotically. With an increase in the Reynolds number, the ratio of the heat transferred into the fluid to the thermal capacity of the fluid shows a decrease. Therefore, the $\mathrm{j}$-factor shows a decrease with an increase in the Reynolds number. The $\mathrm{j}$-factors obtained by an experimental study of Siddique et. al. [2] were also given in Fig.5. As it can be seen, the j-factors obtained in this study shows a similar trend to those obtained experimentally. The differences between the values of $\mathrm{j}$-factor of this study and the experimental study are due to the different geometrical dimensions used in this study and experimental study of Siddique et. al. [2].

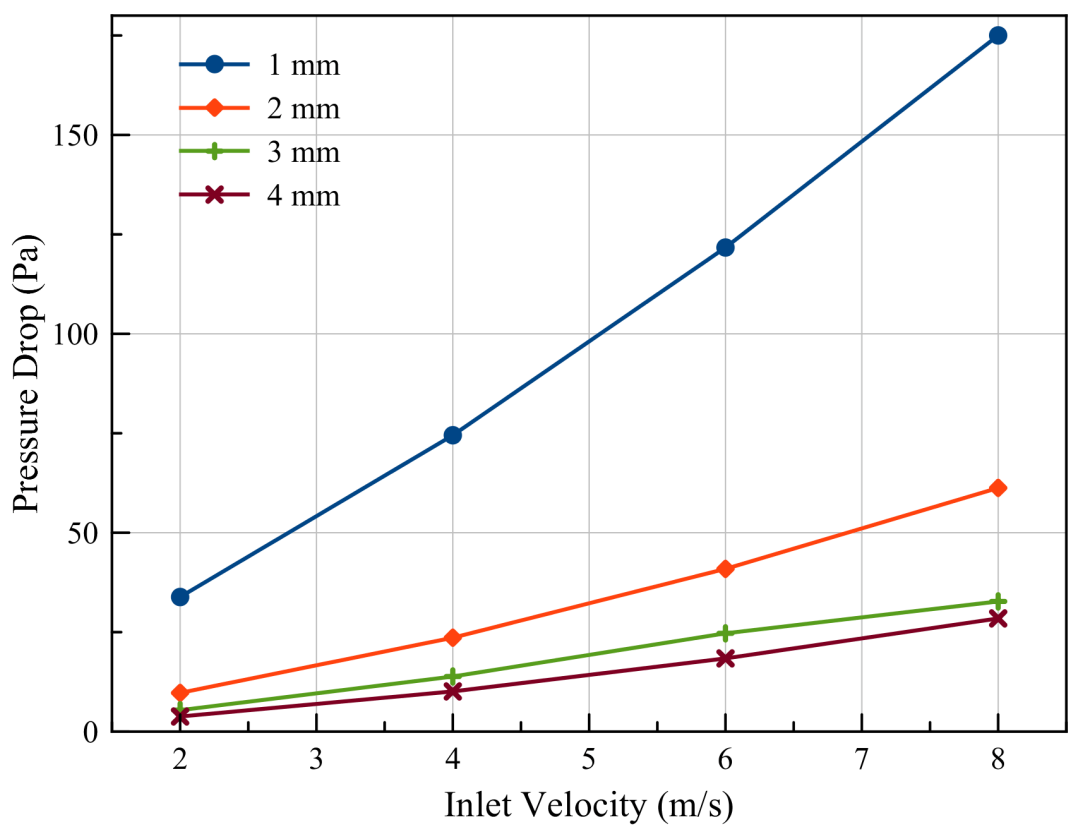

Fig. 6: Variation of pressure drop with inlet velocity.

Another important factor in heat exchanger analysis is the pressure drop of the fluid across heat exchanger as it is the necessary magnitude to calculate the power required to drive the fluid flow. The variation of the pressure drop across the heat exchanger with the inlet velocity is seen in Fig. 6 for various values of the pitch length. As it can be observed from Fig 6 that the pressure drop gets its highest value for the pitch length of $1 \mathrm{~mm}$. It first shows a considerable decrease with an increase in the pitch length and then a lower decrease is seen with further increase in the pitch length. The pressure drop increases with a decrease in the pitch length depending on the increase in the viscous forces. The pressure drop also shows a significant increase with an increase in the inlet velocity, as expected.

The velocity contours at the inlet and outlet region of the computational domain are seen in Fig. 7 and 8 . The flow becomes hydrodynamically developed after some distance from the inlet. The velocity of the airflow is about $4 \mathrm{~m} / \mathrm{s}$ outside the boundary layer for the values of the parameters considered in this figure. The velocity gradient increases considerably by a decrease in the pitch length. This high velocity gradient is the cause of the high pressure drop seen for the low values of the pitch length. As it can be seen in Fig. 8 that a wake region is formed at the outlet region of the heat exchanger. As it was expressed earlier, flow inside the heat exchanger for the considered values of the parameters is laminar. Thus, increasing the mixing of fluid particles by using turbulators or making the slab geometry dimpled would increase the heat transfer rate.

The temperature contours in the computational domain are seen in Fig. 9. The development of thermal boundary layers along the multiport surface are clearly seen from the decreasing temperature gradient along the multiport surface. 


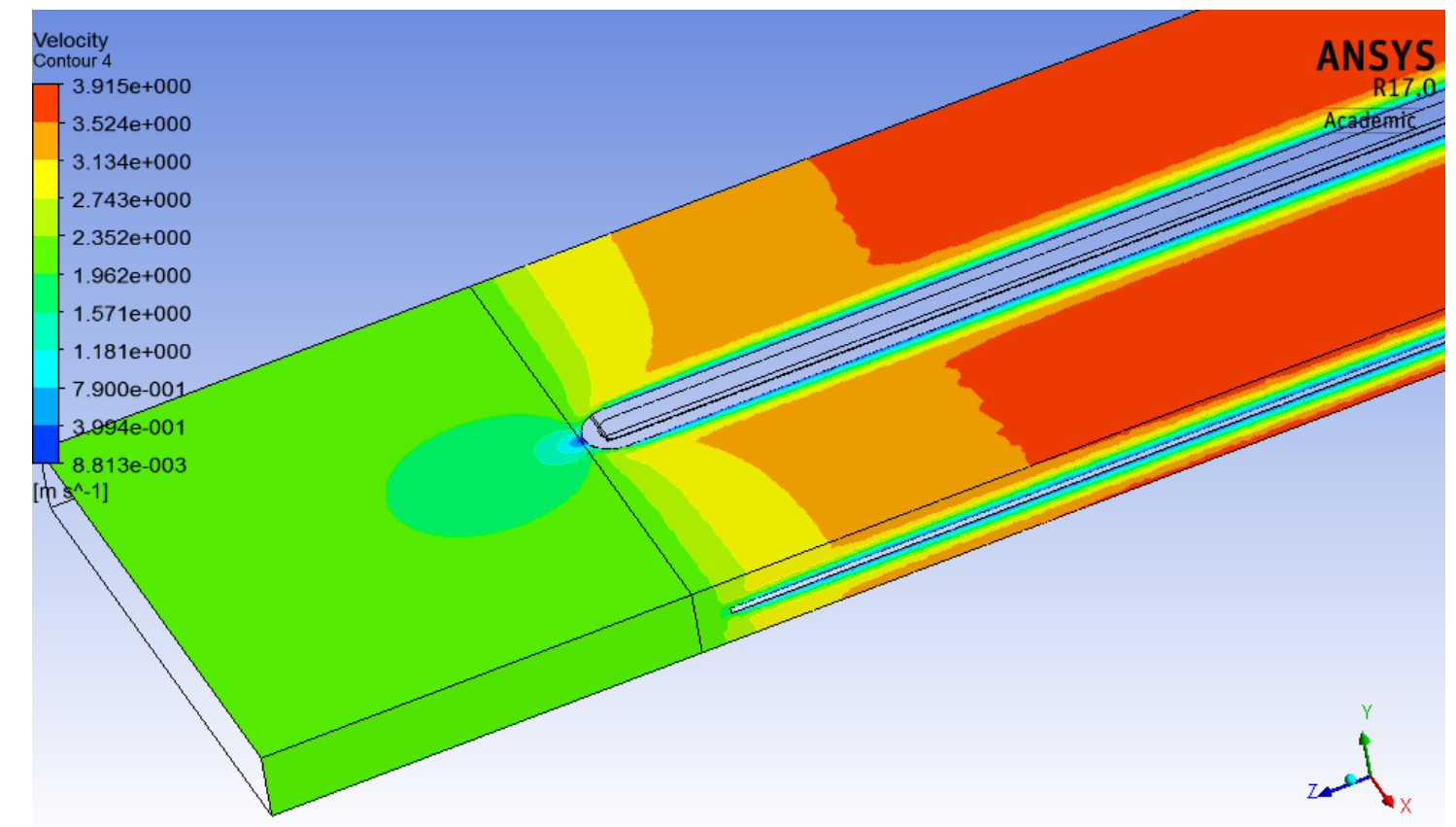

Fig. 7: Velocity contours at the inlet region of computational domain for $2 \mathrm{~mm}$ fin-pitch length and $2 \mathrm{~m} / \mathrm{s}$ inlet velocity.

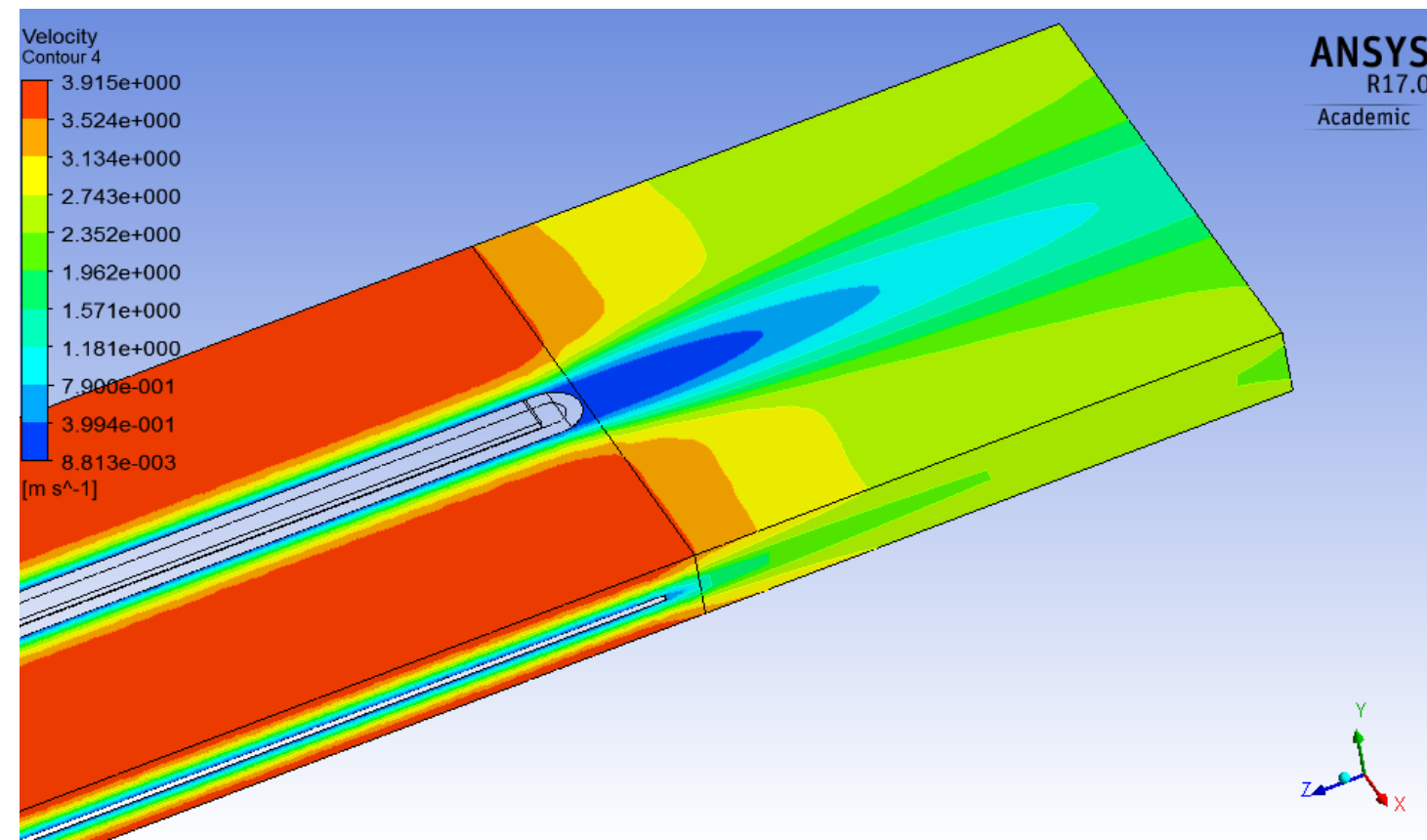

Fig. 8: Velocity contours at the outlet region of computational domain for $2 \mathrm{~mm}$ fin-pitch length and $2 \mathrm{~m} / \mathrm{s}$ inlet velocity.

\section{Conclusions}

Heat transfer and fluid flow in a microchannel heat exchanger were investigated numerically in this study for different values of the pitch length and inlet air velocity. The concluding remarks are: The heat transfer coefficient gets its highest value for the pitch length of $1 \mathrm{~mm}$ while the pressure drop also gets its higher value for the pitch length of $1 \mathrm{~mm}$. Yet the variation of pressure drop with inlet velocity is much higher than the variation of overall heat transfer coefficient with inlet velocity as they can be seen in Fig. 3 and Fig. 6 . Thus, $1 \mathrm{~mm}$ fin pitch length is more favourable to be used in low air velocity applications. Also, as it can be seen in Fig. 3 and Fig. 6; as the fin pitch length becomes wider, the pressure drop and overall heat transfer coefficient variation with fin pitch length becomes smaller. This shows that for larger fin 
pitch lengths, the effect of fin pitch on the heat exchanger performance becomes less significant. Nusselt number shows a significant increase with an increase in the Reynolds number. The j-factor decreases exponentially with an increase in the Reynolds number.

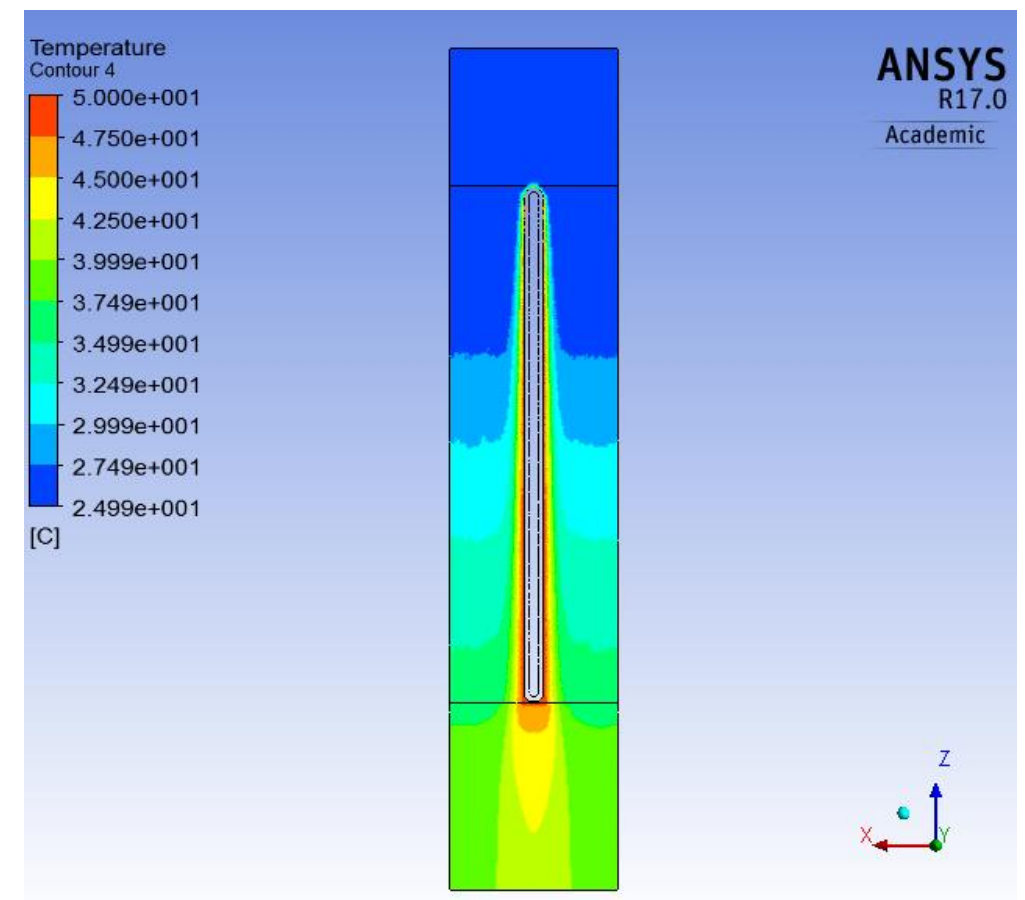

Fig. 9: Temperature contours in the computational domain for $2 \mathrm{~mm}$ fin-pitch length and $2 \mathrm{~m} / \mathrm{s}$ inlet velocity.

\section{References}

[1] E. S. Dasgupta, S. A. Askar, M. Ismail, A. Fartaj and M. A. Quaiyum, “Air cooling by multiport slabs heat exchanger: An experimental approach,” Experimental Thermal and Fluids Science, vol. 42, pp. 46-54, 2012.

[2] F. A. Siddiqui, E. S. Dasgupta and A. Fartaj, "Experimental investigation of air side heat transfer and fluid flow performances of multi-port serpentine cross-flow mesochannel heat exchanger," Int. J. Heat and Fluid Flow, vol. 33, pp. 207-219, 2012.

[3] M. Dehghandokth, M. G. Khan, A. Fartaj and S. Sanaye, "Flow and heat transfer characteristics of water and ethylene glycol-water in a multi-port serpentine meso-channel heat exchanger," Int J. Thermal Sciences, vol. 50, pp. 16151627, 2011.

[4] C. Oliet, A. Oliva, J. Castro and C. D. Perez-Segarra, "Parametric studies on automotive radiators," Applied Thermal Eng., vol. 27, pp. 2033-2043, 2007.

[5] C. Harris, M. Despa and K. Kelly, "Design and Fabrication of a Cross Flow Micro Heat Exchanger," J. Microelectromechanical Systems, vol. 9, no. 4, pp. 502-508, 2000.

[6] M. G. Khan and A. Fartaj, "A review on microchannel heat exchangers and potential applications," Int. J. Energy Research, vol. 35, pp. 553-582, 2010.

[7] L. Sheik Ismail, R. Velraj and C. Rangayakulu, "Studies on pumping power in terms of pressure drop and heat transfer characteristics of compact plate-fin heat exchangers - A review," Renewable and Sustaniable Energy Reviews, vol. 14, pp. 478-485, 2010.

[8] Q. Li, G. Flamant, X. Yuan, P. Neveu and L. Luo, "Compact heat exchangers: A review and future applications for a new generation of high temperature solar recievers," Renewable and Sustainable Energy Reviews, vol. 15, pp. 48554875, 2011.

[9] F. Siddiqui, "A Study of Cross-Flow Air Heating via a Multiport Serpentine Microchannel Heat Exchanger," MSc. dissertation, Dept. Mechanical Automotive and Materials Eng., University of Windsor, Ontario, Canada.

[10] R. K. Shah and D. P. Sekulic, Fundamentals of Heat Exchanger Design. Hoboken, NJ: Wiley, 2003. 